\title{
Elastic-plastic load-carrying capacity of steel members
}

\author{
Pavol Juhas ${ }^{1, *}$ \\ ${ }^{1}$ Institute of Technology and Business in České Budějovice, Okružní 517/10, 37001 České \\ Budějovice, Czech Republic
}

\begin{abstract}
The load-carrying capacity of steel structures and members subjected mostly to bending depends in large measure on local stability of their compressed flanges and bending webs in decided cross-sections and areas. Depending on local stability, the elastic or plastic, eventually the elastic-plastic analysis and design can be applied. The actual standards for design of steel structures contain relatively detailed rules for elastic analysis by the elastic theory and for plastic analysis by the plastic theory. The elastic-plastic analysis and design of steel members are meanwhile still problematic from theory, standard and application point of view. The real elastic-plastic behavior of the steel members is complicated strength and stability problem. Therefore, the representative experimental knowledge and results about the real elastic-plastic behavior and mechanisms of failure of the steel members have been very important from the scientific and applied aspects. The author of paper realized in previous time the wide experimental research within the range of this intention. The paper contains selected knowledge and results of the previous experimental-theoretical investigation of the elastic-plastic local stability of the steel members subjected mostly to bending. The adequate slenderness - strain relation and methodology for practical calculation of the elastic-plastic bending load-carrying capacity of the steel cross-sections and members are presented in the paper.
\end{abstract}

\section{Introduction}

The load-carrying capacity of steel structures and members subjected mostly to bending depends in large measure on the local stability of their compressed flanges and bending webs in decided cross-sections and areas. Depending on local stability, the elastic or plastic, eventually elastic-plastic analysis and design can be applied. The actual standards for design of steel structures contain relatively detailed rules for elastic analysis by the elastic theory and for plastic analysis by the plastic theory. The elastic-plastic analysis and design of steel structures and members is meanwhile still problematic from theory, standard and application point of view, [1-3]. The paper contains selected knowledge and results of the previous experimental-theoretical investigation of the elastic-plastic local stability of the steel members subjected mostly to bending. The adequate slenderness - strain relation and

\footnotetext{
*Corresponding author: juhas@,mail.vstecb.cz
} 
methodology for practical calculation of the elastic-plastic bending load-carrying capacity of steel cross-sections and members are presented and compared with procedures that are applied in some selected standards.

\section{Local stability and classification of steel cross-sections}

The local stability, compactness and slenderness of the steel members and their crosssections are relative. They depend on the loading level or material utilization, and on the buckling resistance of cross-sections and their compressed flanges and bending webs. The buckling resistance and the real behavior of compressed flanges and bending webs depend on more parameters (material properties, geometrical dimensions, material and geometrical imperfection, boundary conditions). Therefore, the steel cross-section compactness or slenderness judgments are complicated stability problem that has been theoretically analyzed through respective differential equation systems [1,2]. For usual cases of the steel cross-sections slenderness $\beta$ (width to thickness ratio) of their webs and flanges is the characteristic parameter of buckling resistance $\left(\beta=d / t_{w}, b / t_{f}, c / t_{f}\right)$, Fig. 1 .
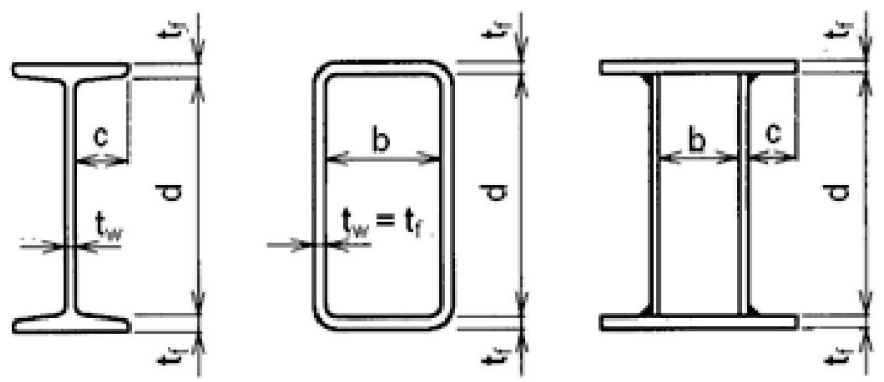

Fig. 1. Usual steel cross-sections and their dimensions.

The new European standard EN 1993-1-1:2005 and transformed national standards for the design of steel structures (CSN EN 1993-1-1, STN EN 1993-1-1 and others) contain the specific classification of the cross-sections due to dimensions and slenderness of their compression and bending parts. In these standards four classes of the cross-sections are defined.

Class 1, 2 and 3 can be considered as the compact or semi-compact cross-sections for the defined level of the material utilization. In this case of the cross-sections the full sectional dimensions can be considered in calculation. Class 4 presents slender crosssections. In this case the effective part of cross-sections must be considered in calculation.

The standards define maximal values of the slenderness $\beta$ for individual webs and flanges of the cross-sections subjected to compression or bending, otherwise combined compression and bending: $\beta_{01}$ for class $1, \beta_{02}$ for class 2 and $\beta_{1}$ for class 3 .

The web slenderness $\beta_{1}$ is very important for the standards and practical design of steel cross-sections. If slenderness of the web $\beta=\beta_{1}$, then with full elastic bending moment $\mathrm{M}_{\mathrm{el}}$ of the cross-section can be calculated by simple bending theory,

$$
\mathrm{M}_{\mathrm{el}}=\mathrm{f}_{\mathrm{y}} \mathrm{W}_{\mathrm{el}} \text { or } \mathrm{M}_{\mathrm{el}}=\mathrm{f}_{\mathrm{y}} \mathrm{W}_{\mathrm{el}} \gamma_{\mathrm{M} 0},
$$

where $f_{\mathrm{y}}$ is the yield stress, $\mathrm{W}_{\mathrm{el}}$ is the elastic cross-section modulus and $\gamma_{\mathrm{M} 0}$ is the material partial factor. 
The exact estimation of the limit web slenderness $\beta_{1}$ is problematic, because it depends on real boundary conditions and on production imperfections. Only the classic critical conception allows clearly determination of the web slenderness $\beta_{1}$. According to this conception the critical normal stress for the elastic limit stage

$$
\sigma_{\mathrm{kr}}=\mathrm{k}_{\sigma} \sigma_{\mathrm{E}}=190000 \mathrm{k} \sigma / \beta^{2}
$$

and relative web's slenderness

$$
\beta_{1}=435.89 \sqrt{k_{\sigma} / f_{y}}=28.43 \sqrt{k_{\sigma}} \sqrt{235 / f_{y}}
$$

For the web with pin supporting along both longitudinal borders subjected to bending $\mathrm{k}_{\sigma, \min }=23.88$ and if the steel $\mathrm{S} 235$ with $\mathrm{f}_{\mathrm{y}}=235 \mathrm{MPa}$ is assumed, then $\beta_{1}=138,95$. In accordance with the critical conception was defined the web slenderness $\beta_{1}$ in the previous design standard CSN/STN 73 1401:1984, [3].

The new standards take into consideration the effect of initial production imperfections (material and geometrical), therefore the limit web slenderness $\beta_{1}$ is smallest. According to the European standard EN 1993-1-1 and transformed national standards CSN EN 1993-1-1 and STN EN 1993-1-1 the limit web slenderness

$$
\beta_{1}=124 \sqrt{235 / \mathrm{f}_{\mathrm{y}}}
$$

If the web slenderness $\beta<\beta_{1}$, than the elastic-plastic bending moment $M_{\text {ep }}$ or full plastic bending moment $\mathrm{M}_{\mathrm{pl}}$ of the cross-section can be calculated,

$$
\begin{aligned}
& M_{e p}=f_{y} W_{e p} \text { or } M_{e p}=f_{y} W_{e p} \gamma_{M 0}, \beta 02<\beta<\beta_{1} \\
& M_{p l}=f_{y} W_{p l} \text { or } M_{p l}=f_{y} W_{p l} \gamma_{M 0}, \quad \beta \leq \beta_{01}
\end{aligned}
$$

$\mathrm{W}_{\mathrm{ep}}$ and $\mathrm{W}_{\mathrm{pl}}$ are the elastic-plastic and full plastic modulus of the cross-section.

According to the European standard EN 1993-1-1 and transformed national standards CSN EN 1993-1-1 and STN EN 1993-1-1 the limit web slenderness

$$
\beta_{01}=72 \sqrt{235 / f_{y}} \text { and } \beta_{02}=83 \sqrt{235 / f_{y}}
$$

\section{Elastic-plastic bending load carrying capacity}

The elastic-plastic bending moment $\mathrm{M}_{\mathrm{ep}}$ and the full plastic bending moment $\mathrm{M}_{\mathrm{pl}}$ of the cross-sections depend mostly on the actual material properties of the applied structural steel, development of plastic strains $\varepsilon$ and buckling resistance of the bending web and compression flange.

Buckling resistance or local stability of the steel member webs subjected to bending in the elastic-plastic stadium $\left(\beta<\beta_{1}\right)$ can be sufficient accurately defined by limit strains $\varepsilon_{\mathrm{u}}$ in the most stressed border of its compressed part $\left(\varepsilon_{\mathrm{u}}>\varepsilon_{\mathrm{y}}\right)$.

The real elastic-plastic behavior of the steel members and their bending webs and compressed flanges is complicated. Therefore, the representative experimental knowledge and results about the real elastic-plastic behavior and mechanisms of failure of the steel members have been very important from the scientific and practical aspects. Therefore, the 
author of paper realized in previous time the wide experimental research with such intention. The static schemes of the tested steel beams are illustrated in Fig. 2, [4].

N11, N12, N13, N14

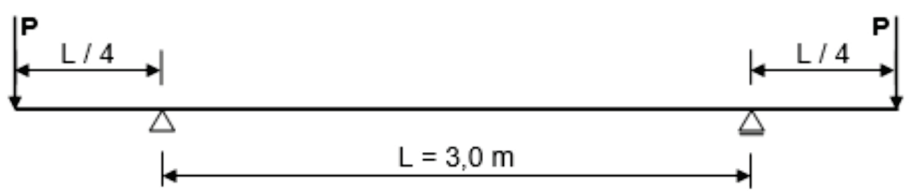

N21, N22, N23, N24

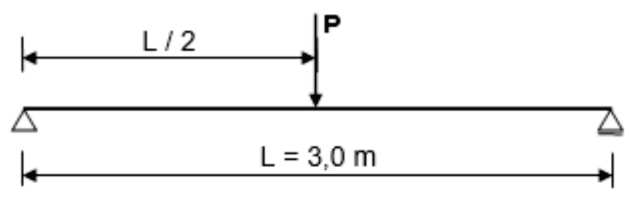

\section{N31, N32, N33, N34, N41, N42, N43, N44}

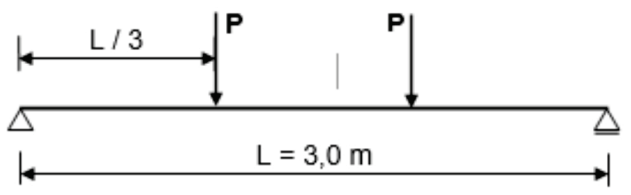

P11, C12, P13, C23

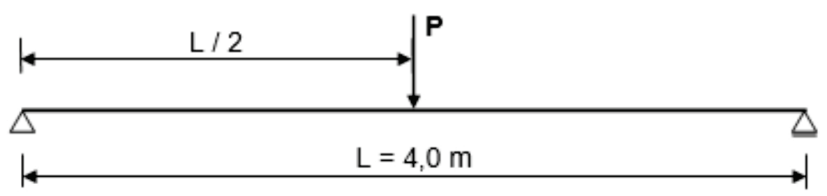

C11, R11, R12, C13, R13, C21, R21, C22, P22, R22, P23, R23

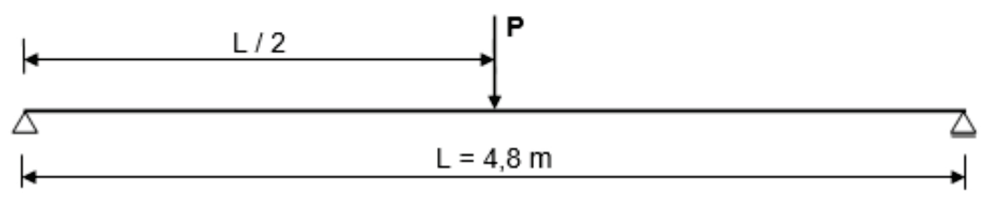

Fig. 2. The static schemes of tested steel beams.

The tested beams had different cross-section dimensions and slenderness of their webs The tests continued till elastic-plastic failure. The local tranverse buckling w and strains $\varepsilon$ were measured and evaluated during the tests.

Following experimental and related theoretical results the author of paper worked out the original methodology for calculation of the elastic-plastic bending load-carrying capacity of the steel members $M_{e p}$ with taking account local stability aspects [3, 4, 6-10]. 
This methodology is based on the development of plastic strains $\varepsilon$ in the most stressed cross-section. This development is defined by limit strains $\varepsilon_{\mathrm{u}}$ in the edge fibers of web compressed part subjected to bending. The authors'relation $\varepsilon_{u}-\beta$ is presented in Fig. 3.

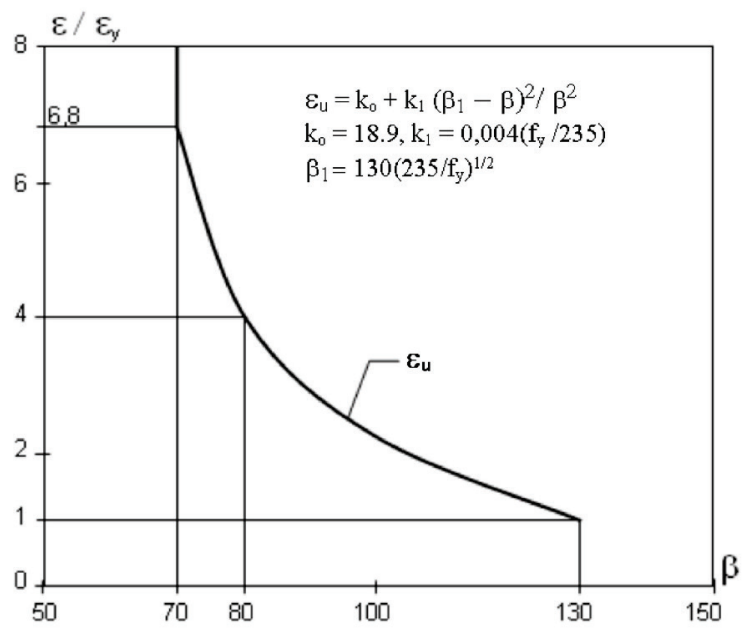

Fig. 3. The authors' relation of the limit strains $\varepsilon_{\mathrm{u}}$ to web slenderness $\beta$, steel S 235 .

The presented methodology and relation $\varepsilon_{\mathrm{u}}-\beta$ allow to calculate the elastic-plastic bending moment $M_{\mathrm{ep}}$ of the cross-section if the web slenderness $\beta_{02}<\beta<\beta_{1}$. For the symmetrical I cross-section

$$
\mathrm{M}_{\mathrm{ep}}=\mathrm{M}_{\mathrm{pl}}-\mathrm{M}_{\mathrm{el}, \mathrm{w}}\left(\varepsilon_{\mathrm{y}} / \varepsilon_{\mathrm{u}}\right)^{2}
$$

$\mathrm{M}_{\mathrm{el}, \mathrm{w}}$ is the elastic-plastic bending moment of the web.

The previous authors' linear relation $\mathrm{M}_{\mathrm{ep}}-\beta$ has had form [4]:

$$
\mathrm{M}_{\mathrm{ep}}=\mathrm{M}_{\mathrm{pl}}-\left(\mathrm{M}_{\mathrm{pl}}-\mathrm{M}_{\mathrm{el}}\right)\left[\left(\beta-\beta_{02}\right) /\left(\beta_{1}-\beta_{02}\right)\right] .
$$

The similar linear relation is also applied in Specification AISC LRFD:1999. The limit slendernesses $\beta_{0}$ and $\beta_{1}$ are, however, different.

The standard EN 1993-1-1:2005 (CSN/STN 1993-1-1) contains some procedure for the calculation of the elastic-plastic bending moment $\mathrm{M}_{\mathrm{ep}}$ by the effective cross-section of class 2, which is presented in the Fig. 4.

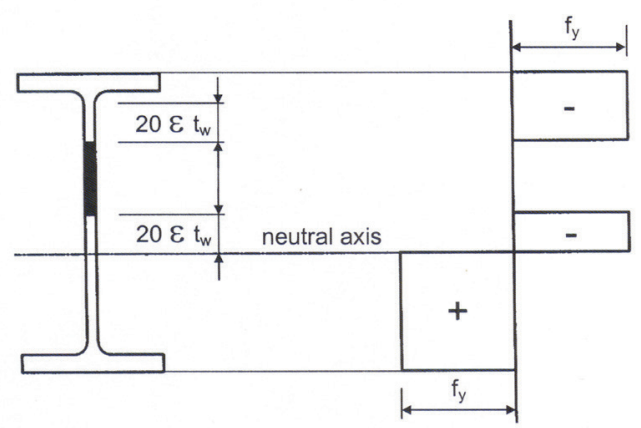

Fig. 4. The effective cross-section class 2 by standard EN 1993-1-1:2005. 
It is clear from Fig. 4 that the assumed effective cross-section by EN 1993-1-1:2005 and relative national standards is in conflict with assumptions of the simple bending theory and the experimental knowledge.

\section{Conclusions}

The obtained and partially presented research knowledge and results have allowed following conclusions:

- The elastic-plastic load-carrying capacity of the steel members and their cross-sections at large measure depends on local stability of their webs and flanges subjected to bending and compression.

- The local stability of the steel member webs and flanges subjected to bending and compression depends on the real development of the elastic-plastic strains $\varepsilon$ in the most stressed cross-sections and areas.

- According to the experimental and theoretical results the relation for limit plastic strains $\varepsilon_{\mathrm{u}}$ and web slenderness $\beta$ has been established.

- The proposed relation $\varepsilon_{\mathrm{u}}-\beta$ allows common classification of the steel member crosssections from the local stability aspects in accordance with expected or selected development of plastic strains $\varepsilon$.

- The proposed methodology enables to calculate the elastic-plastic bending load-carrying capacity of steel members depending on the development of plastic strains $\varepsilon$ in the most stressed cross-sections and areas.

The presented research knowledge and results and their normative and practical application have supported the economical and reliability design of the steel members and structures.

\section{References}

1. A. Mrazik, M. Skaloud, M. Tochacek, Plastic Design of Steel Structures (Ellis Horwood Limited, Chichester and Prague, 1986)

2. J. Djubek, R. Kodnar, M. Skaloud, Limit State of the Plate Elements of Steel Structures (Birkhäuser Verlag, Basel, 1983)

3. P. Juhas and col., Design of Steel Structures - Commentary to STN 73 1401:1998, (Slovak Institute for Standardization, Bratislava, 2001)

4. P. Juhas, Building Research Journal 32(3), 833-863 (1984)

5. M. A. Bratford, De Luca, Journal of Constructional Steel Research, 7, 317-334 (1987)

6. P. Juhas, Stavební obzor 3(3), 88-93 (1994)

7. P. Juhas, Ocelove konstrukce, 2/2, 13-15,43-45 (2000)

8. P. Juhas, Selected Scientific Paper, 1, 7-21 (2005)

9. P. Juhas, Mechanics and Material, ASCE/ASME/SES, Baton Rouge (2005)

10. P. Juhas, Challenges, Opportunities and Solutions in Structural Engineering Construction (Taylor and Francis Group, London, 2010) 